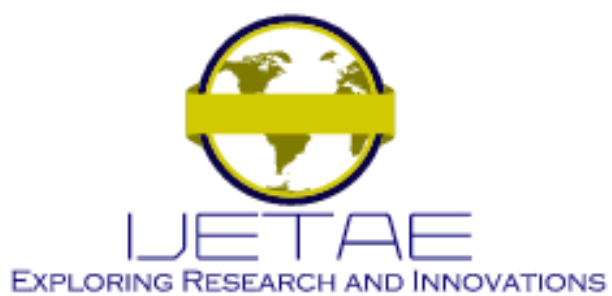

International Journal of Emerging Technology and Advanced Engineering

Website: www.ijetae.com (E-ISSN 2250-2459, Scopus Indexed, ISO 9001:2008 Certified Journal, Volume 12, Issue 01, January 2022)

Manuscript Received: 02 December 2021, Received in Revised form: 04 January 2022, Accepted: 10 January 2022

DOI: 10.46338/ijetae0122_04

\title{
Design of an Intelligent Garbage Container that Allows to Monitor the Waste for its Proper Collection
}

\author{
Robert Cerna-Duran ${ }^{1}$, Brian Meneses-Claudio ${ }^{2}$, Alexi Delgado ${ }^{3}$ \\ ${ }^{1,2}$ Universidad de Ciencias y Humanidades \& Av. Universitaria 5175, Los Olivos 15304 \\ ${ }^{3}$ Pontificia Universidad Católica del Perú \& Av. Universitaria 1801, San Miguel 15088
}

\begin{abstract}
The increase in garbage production today is due to the exponential growth of the population worldwide, due to the fact that thousands of tons of garbage are generated daily around the world, but the mismanagement that gives them has become an environmental problem since $33 \%$ of all the garbage generated is not recycled, for that reason it is estimated that within the next three decades the amount of waste worldwide will increase to $70 \%$. That is why in the present research work it is proposed to make an intelligent system based on the Internet of Things (IoT) that allows monitoring the garbage containers in real time representing with percentages the state of these containers and these can be collected in time by garbage trucks, and thus avoid the increase of garbage in the streets and the various types of problems that these would cause. As a result, it was obtained that the System does comply with the established conditions because it allows to monitor in real time representing by percentages the state of the garbage container, which indicates $\mathbf{4 0 \%}$ as almost full and $\mathbf{8 0 \%}$ indicates that it is already available for collection. Finally, it is concluded that using the Garbage Container Monitoring System will allow to better optimize the collection process and, in addition, the problems that are usually perceived today due to the amount of garbage that are registered in the streets will decrease.
\end{abstract}

Keywords-- Internet of Things; Intelligent system; Real time; Environmental Problem; Monitoror; Percentage.

\section{INTRODUCTION}

The levels of waste we produce around the world have risen rapidly over the past few decades, but we are not responding to this. This is what a recent report by the British organization Verisk Maplecroft denounced, which warns of a "growing crisis" of waste, caused by plastic. The risk analysis team found that more than 2100 million tons of waste are generated worldwide each year, which could cover an average of more than 800,000 Olympic swimming pools. Only $16 \%$ equivalent to 323 million tons of this waste is recycled. The United States is the country that generates the most waste per person worldwide, that is, of the global average three times more [1].
Colombia generates around 11.6 million tons of municipal solid waste each year, of which only $17 \%$ is recycled. In this sense, the city of Bogotá is one of the most populated cities in the country, generating around 6,308 tons per day, a serious socio-environmental problem. People are involved in it because they are not familiar with waste management and selective collection, in addition the company that provides the service does not collect immediately, therefore, there is an increase in dump areas in the streets, which causes pollution of the landscape, bad odors and an increase in rodents in the streets, endangering people's health and well-being [2].

In Peru the situation is alarming, with more than 7 million tons of municipal solid waste generated each year; around 20000 tonnes per day and an average of almost 1000 tonnes per hour, yet $1.9 \%$ of usable solid inorganic waste is recycled. They are currently one of the biggest problems in the world and this is a cause for concern because more products have been created in recent years and of course the production of waste has also increased [3]. Likewise, fragments of microplastic per square meter are also recorded in sandy beaches of the Peruvian coasts [4].

The objective of the research work is to design a system that allows to identify the state of a garbage container, so that when the garbage of these containers exceeds the limit, the designed system sends information to the municipality so that they can be collected by garbage trucks. For the elaboration of the design, ultrasonic sensors were used to detect the level of the container and send information to the WIFI ESP32 module so that it communicates through the internet. Like the research work of [8] the system will communicate over the Internet.

Currently there are various types of electronic devices that we use in our daily lives to connect to the internet, interact through them and share information, that is why we will use for this project a WIFI ESP32 module, apart from being economical it is mostly used in applications related to the Internet of Things (IOT), because it allows you to connect to the internet and interact with several devices that connect to it. [9] 


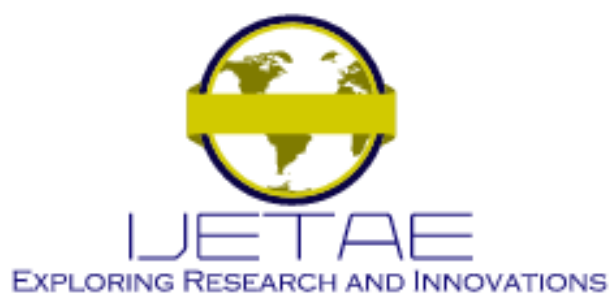

International Journal of Emerging Technology and Advanced Engineering Website: www.ijetae.com (E-ISSN 2250-2459, Scopus Indexed, ISO 9001:2008 Certified Journal, Volume 12, Issue 01, January 2022)

Ultrasonic sensors are electronic devices that work by bouncing sound waves and are used to detect the presence of an object with a working frequency above the sound wave of $20 \mathrm{kHz}$ at $2 \mathrm{MHz}$ ultrasonic and is measured with the time it takes for the bounce to arrive from the object. That is why in the present work ultrasonic sensors were used to detect the garbage in the container. [10]

The work developed is structured as follows, in section II that belongs to the methodology will be announced about the devices to be used in the system, its operation and the advantage of implementing the system. In the Ill section the results obtained will be discussed and finally in the $1 \mathrm{~V}$ section the conclusion of the project will be argued.

\section{LITERATURE REVIEW}

In [5], he analyzes the problems related to the environment highlighting the lack of practice since in the area where I registered for these problems was in the corners of the district of villa el Salvador, he noticed or that a lot of waste was thrown which obviously causes environmental pollution, likewise he saw that containers were missing in some area of the place, in the same way he noticed the lack of commitment on the part of the people who live near the area. It is for that reason that he decided to implement intelligent ecological containers that measure the volume of these, to perform the indicated use or ultrasonic sensors to measure the level of the container, as a security measure a flame detector, Arduino Uno, lora shield, smartBin sensor was used to create auto or nuanced routes and WAN lora for data transmission between nodes. With this system he proposed or improved the waste management of that place to motivate people to recycle. Through the level sensor it is intended to obtain the filling of the container, but to have accurate calculations about the amount of waste that will occupy the containers, proceeded to carry out studies where I obtained or the necessary data and with those margins implementor the exact amount of intelligent containers, likewise the system was inserted a flame sensor to avoid fires, these signals are sent to the Arduino Uno that is in charge of sending the data to the gateway, this process was based on the Internet of Things since it benefits energy savings and is also economical.
From the results it was possible to design the intelligent container, calculate the volume that the intelligent container must have with respect to the people of a group of the place, the number of containers that will be required, in this case there were 24 containers, the components of the proposed system were defined, the means of transmission of the intelligent container and the gateway. Regarding the project, it is concluded that the smart container is a solution option to improve the management of solid waste both in social, economic, and environmental issues.

In [6],they analyze the huge increase in garbage involving plastic household waste, specifying that it is a threat to both the human race and the environment therefore they indicate that it is not too late to look for a solution that addresses this problem. That is why they propose to make a useful system based on the Internet of Things (IoT) with the ability that they can monitor in real time the daily garbage using intelligent technology with the main contribution of the WeMos D1 mini card and ultrasonic sensors. To do this, what they do is place an ultrasonic sensor in the garbage container so that they can monitor the level of garbage, this sensor is connected to the WeMos D1 mini that has the integrated $\mathrm{Wi}-\mathrm{Fi}$ capabilities to send registered information to the garbage monitoring system either building, municipality, shopping centers, or to the same garbage collection truck so that it can pick it up. As a result it was obtained that the values of the sensor are almost accurate to the state of the garbage can since it had an error distance of less than $1 \mathrm{~cm}$, likewise the data obtained from the sensor in real time had a delay of less than 1 second, they also recorded that the schedules of the day affect the system due to the maximum distance between nodes, revealing that at night the Wi-Fi range is better than in the morning and afternoon. From this project they conclude that the distance values received were accurate and in real time, also highlight that they can be extended to several buckets, to automate the collection of garbage throughout the city.

In [7], they analyze that the increase in garbage is increasingly high due to the increase in population, therefore, they indicate that garbage accumulates in certain areas where it should not be, they also highlight that it not only generates health problems but also unpleasant odors for the residents of the area. 


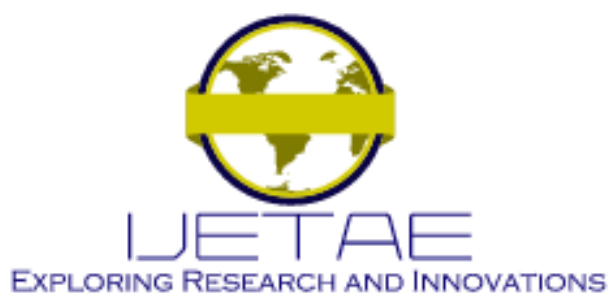

International Journal of Emerging Technology and Advanced Engineering Website: www.ijetae.com (E-ISSN 2250-2459, Scopus Indexed, ISO 9001:2008 Certified Journal, Volume 12, Issue 01, January 2022)

That is why they propose an intelligent garbage monitoring system based on Arduino and sensors such as nodes that monitor the status of the garbage container, so the system can communicate with the database to provide information about the status of the container and sample it on a web page in such a way that routes are generated so that the authorities belonging to the given area are more alert and avoid the problems that causes the accumulation of garbage in the streets. To do this, what they do is a network of one-hop sensors in order for them to communicate with the server, making each sensor node have a unique identification number (ID) that makes an entry into the database and allows to identify in colored icons the status of each container so that the server information is accessible through a compatible application with a mobile phone or other device that connects to the website. As a result, it was obtained that the implementation of the sensor node was successful, likewise the website allowed the user to see information on the status of the containers through mobile applications, the icons of the mobile application changed color every time the level of garbage in the containers increased, where it indicated that $70 \%$ represented with the red icon could already be collected. The authors conclude that the developed system offers many useful features for any city looking to improve its solid waste collection technique, as well as minimize overall collection costs. In addition, they indicate that this not only gives municipal waste management agencies the ability to better manage their waste, but also offers better forecasting and resource planning capabilities that reduce container overfilling.

\section{METHODOLOGY}

In this section we will show the process by which the system will be based for its proper operation. In Figure 1. The flow diagram of the system that will allow the monitoring of waste containers is appreciated.

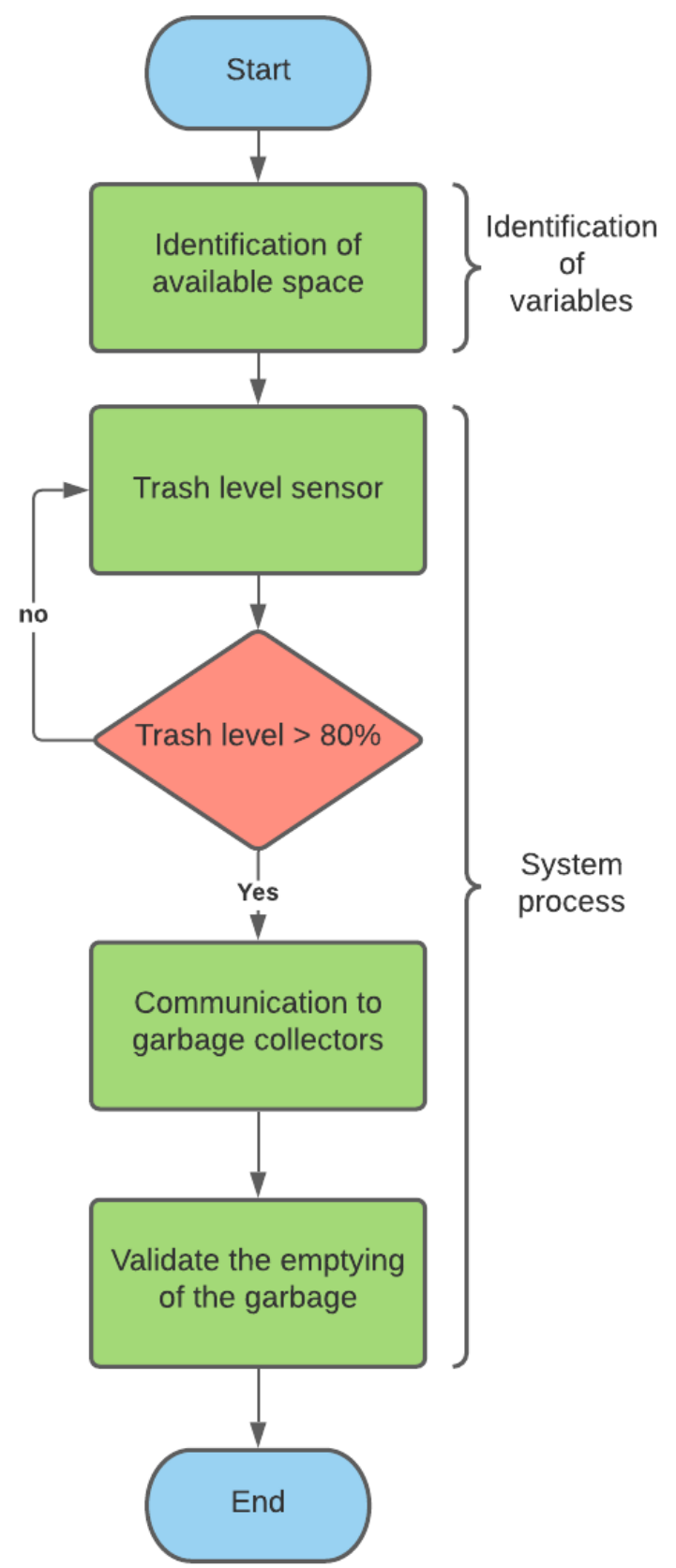

Figure 1. Solid Waste Monitoring System Flowchart 


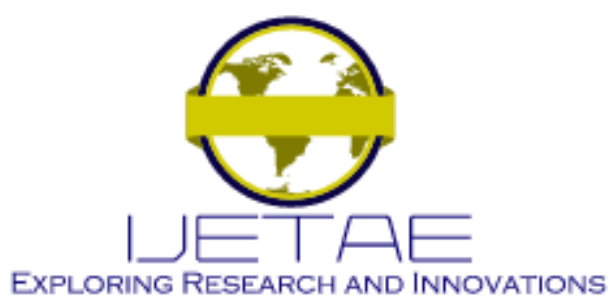

International Journal of Emerging Technology and Advanced Engineering Website: www.ijetae.com (E-ISSN 2250-2459, Scopus Indexed, ISO 9001:2008 Certified Journal, Volume 12, Issue 01, January 2022)

\section{A. Variable Identification}

In this part what will be announced are the characteristics of the waste container, as well as the electronic components that will be used. It is of the utmost importance to know the characteristics of the waste container shown in Table I, since thanks to its available space it will be possible to collect a large amount of solid waste, as well as prevent the components from being damaged in case any type of liquid is thrown into it because it includes a drain at the bottom [11]. Figure 2 shows the waste container.

TABLE I.

Characteristics of the dumpster

\begin{tabular}{|l|l|c|}
\cline { 2 - 3 } \multicolumn{1}{c|}{} & \multicolumn{2}{c|}{ Key features } \\
\hline \multirow{4}{*}{$\begin{array}{l}\text { Waste } \\
\text { container }\end{array}$} & Width & 1.07 meters \\
\cline { 2 - 3 } & Long & 1.37 meters \\
\cline { 2 - 3 } & Height & 1.35 meters \\
\cline { 2 - 3 } & Weight & 50 kilograms \\
\cline { 2 - 3 } & Capacity & 510 kilograms \\
\hline
\end{tabular}

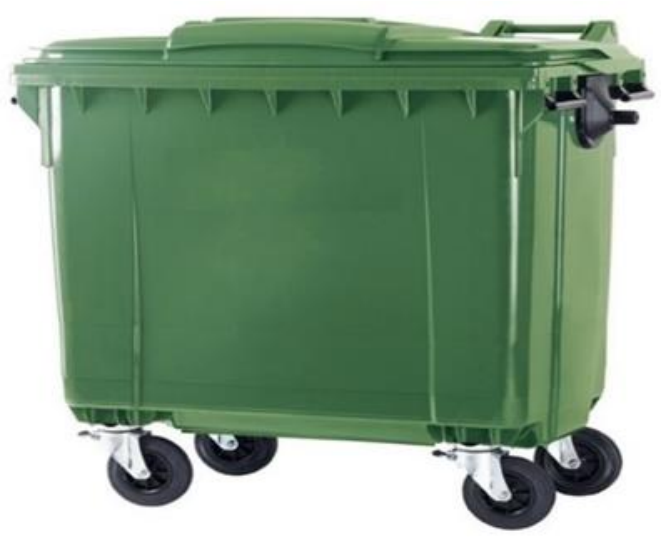

Figure 2. Waste container

To provide information on the waste containers, the esp32 module was used, unlike its predecessors, it is small and has several especially important characteristics, as shown in Table II. These devices allow their connection through the internet either by means of a computer or a mobile device to control them or receive information, in addition These microcontrollers can be programmed with Arduino IDE (Integrated Development Environment), which facilitates their use [12]. Figure 3 shows the esp32 module.
TABLE II.

Features of the ESP32 module

\begin{tabular}{|l|l|}
\hline \multicolumn{2}{|c|}{ Module esp32 } \\
\hline Entry limit & $1 \mathrm{~V}-2 \mathrm{~V}-4 \mathrm{~V}$ \\
\hline RAM & $520 \mathrm{~kb}$ \\
\hline Way & $\begin{array}{l}\text { Ultra-low power } \\
\text { consumption }\end{array}$ \\
\hline GIPIO & 36 \\
\hline Converter & ADC 12Bit \\
\hline Interfaces Ethernet & MAC \\
\hline Integrates & $\begin{array}{l}\text { Wi-Fi and } \\
\text { Bluetooth }\end{array}$ \\
\hline 2 & $\begin{array}{l}\text { UART or serial } \\
\text { doors }\end{array}$ \\
\hline Dual-core processor & Up to $240 \mathrm{MHz}$ \\
\hline
\end{tabular}

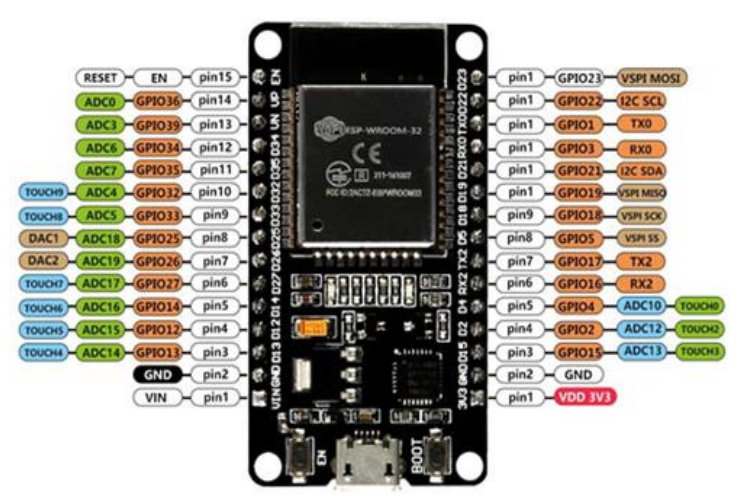

Figure 3. ESP32 Module

Like [13], ultrasonic sensors from the HC-SR04 model shown in Figure 4 were used for the detection of the amount of garbage in the container, and their characteristics are shown in Table III. These types of sensors are applied especially for the detection of objects with a good millimeter accuracy, because of these actions it is dependable in all conditions. Its operation is based on the generation of high frequency pulses that travel through the air and this when hitting an obstacle is reflected in the receiver with the same time it was emitted, also allows to calculate its distance, and its operation is not involved by black materials or sunlight. 


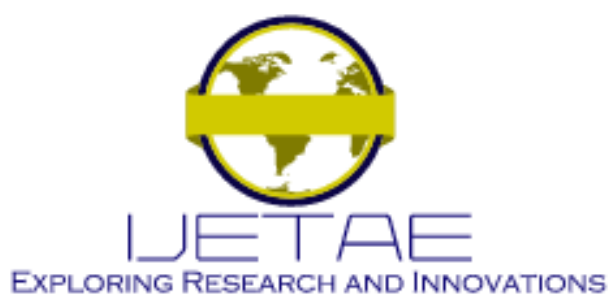

International Journal of Emerging Technology and Advanced Engineering

Website: www.ijetae.com (E-ISSN 2250-2459, Scopus Indexed, ISO 9001:2008 Certified Journal, Volume 12, Issue 01, January 2022)

TABLE III.

Features of the HC-SR04 ultrasonic sensor

\begin{tabular}{|c|c|}
\hline Has four pins & $\begin{array}{l}\text { Ground (GND), } \\
\text { receiver (Echo), trigger } \\
\text { (Trigger) and power } \\
\text { (VCC), }\end{array}$ \\
\hline Ultrasonic frequency & $40 \mathrm{Khz}$ \\
\hline Feeding & $5 \mathrm{~V}$ \\
\hline Consumption & $15 \mathrm{~mA}$ \\
\hline Distance & $2 \mathrm{~cm}-400 \mathrm{~cm}$ \\
\hline
\end{tabular}

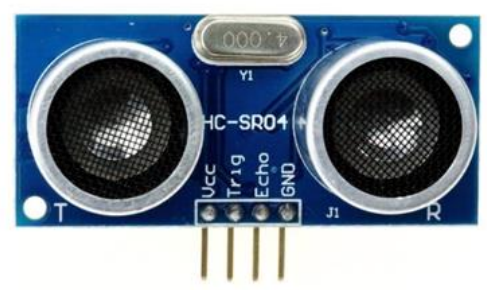

Figure 4. Ultrasonic sensor HC-SR04

The operation of the sensors is of utmost importance since they will be in charge of detecting the amount of garbage in the container, for that reason the sensors are located at certain distances to be able to know the percentage of filling (sensor 1 located at $0.54 \mathrm{~m}$ equivalent to $40 \%$, sensor 2 located at $1.08 \mathrm{~m}$ equivalent to $80 \%$ ), in the same way, the esp32 module will be located between the sensors in order to receive the detected signals. Figure 5 shows the locations of the electronic devices in the waste bin.

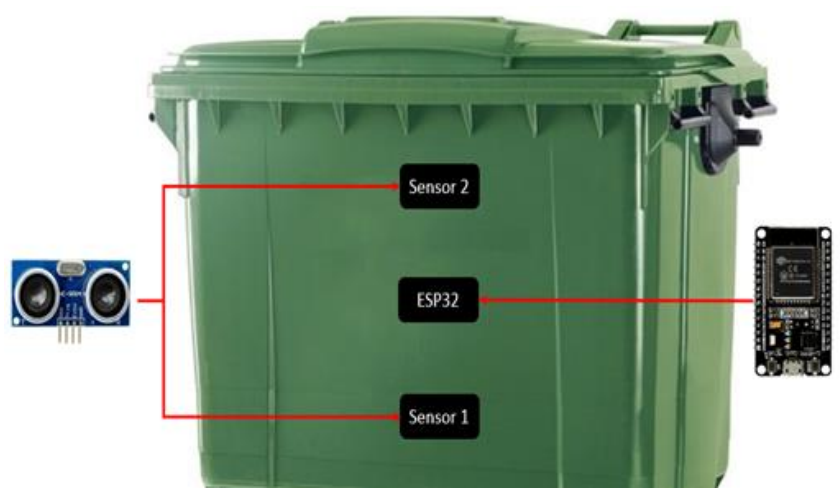

Figure 5. Location of electronic devices in the container

\section{B. System Process}

The system will send information about the overfilling of the waste container if the second sensor remains active since this sensor when kept active what it will do is inform that the amount of waste in the container is at $80 \%$ to proceed with its respective collection and prevent the container from filling completely. Figure 6 shows the sensors in operation which indicates that it can already be collected by waste trucks.

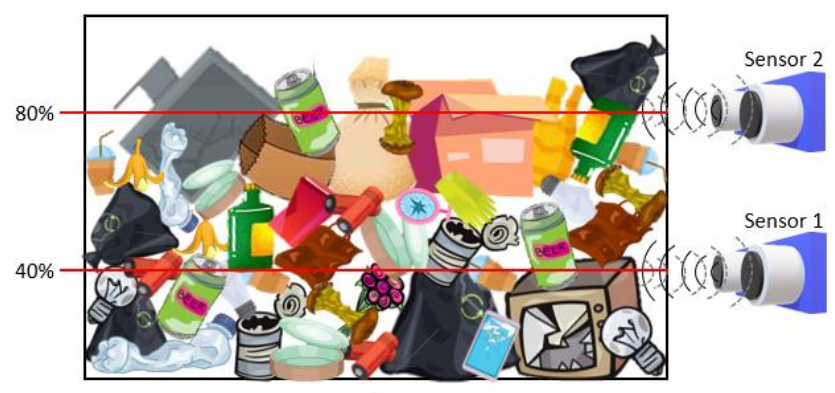

Figure 6. System in operation

In case only the first sensor is activated as shown in Figure 7 , it will indicate with $40 \%$ that the waste container with respect to the established limit is in the middle, which will logically announce that if the filling process is being conducted.

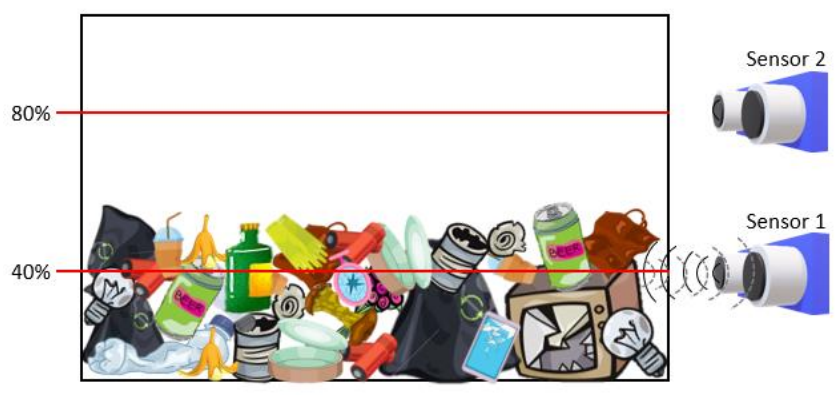

Figure 7. Detection of the first sensor

In this case the sensors do not detect any obstacle since the amount of waste in the container is not enough for the first sensor and much less the second sensor to start acting, so that the system will not send any information regarding the state of the container. Figure 8 shows that both sensors are not in operation. 


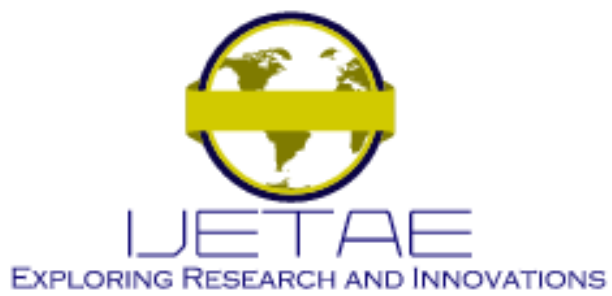

International Journal of Emerging Technology and Advanced Engineering Website: www.ijetae.com (E-ISSN 2250-2459, Scopus Indexed, ISO 9001:2008 Certified Journal, Volume 12, Issue 01, January 2022)

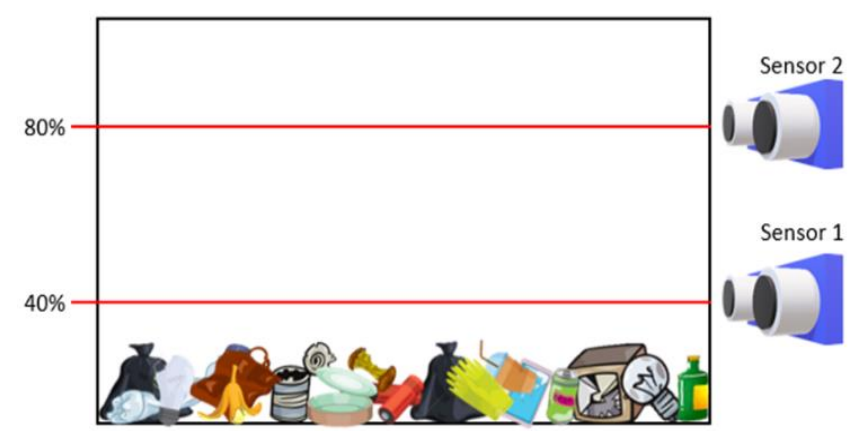

Figure 8. Undetected sensors

For the monitoring of the waste container two ultrasonic sensors were used to identify the level of waste in the container, these sensors will be connected to the ESP32 module in order that this module can send information regarding what is registered by the sensors through a web server, When the first sensor is activated the esp32 module will send information indicating that the container is at $40 \%$ and if the second sensor is activated it will inform that the container is at $80 \%$ being already accessible for collection and this can communicate with the municipality through a website that is compatible with a computer, also with a smart mobile phone so that they are up to date with the collection and can order the waste trucks to empty the containers before they are filled completely. Figure 9 shows the communication between the devices through the Internet.

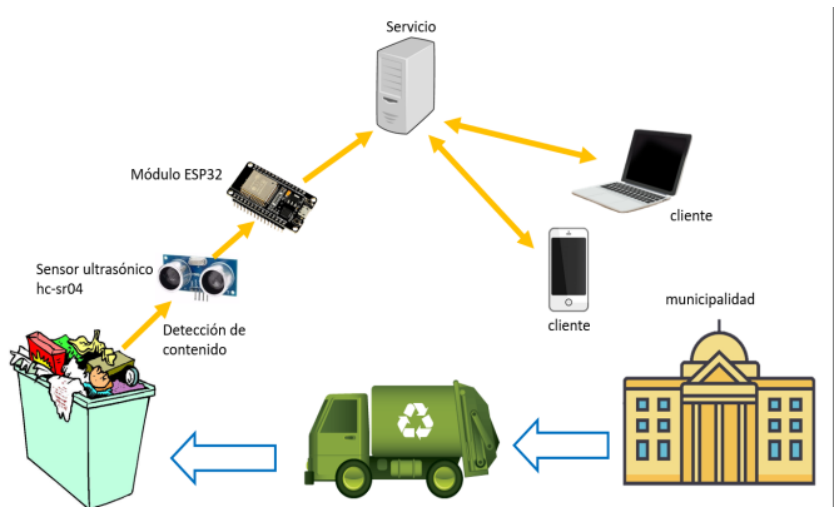

Figure 9. Communication between devices
As shown in Figure 10 the system operates with two ultrasonic sensors where the Trigger of the first sensor is connected to pin D22 of the esp32, in which it will send a pulse of 10us to the Trigger to start the remote detection cycle, which would be 8 pulses with a frequency of $40 \mathrm{khz}$, and the "Echo" of the sensor uses the D33 pin of the module to receive it, in the same way the second sensor will operate in the same way as the first, but will provide different information. the system was designed to detect obstacles at a distance of less than $10 \mathrm{~cm}$.

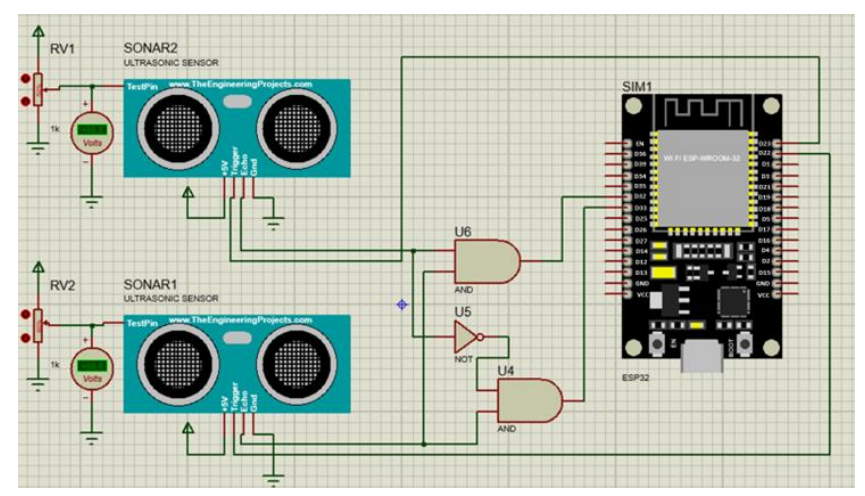

Figure 10. System circuit in Proteus

\section{RESULTS}

What was done in this part was to check the ultrasonic sensors, and for this use the necessary materials such as the protoboard and the cables for the proper connection.

\section{- First ultrasonic sensor}

Figure 11 shows the connections of the electronic devices of the implemented system, which would be the ESP-32, logic gates and the first ultrasonic sensor that will be able to measure especially $40 \%$ of the waste container.

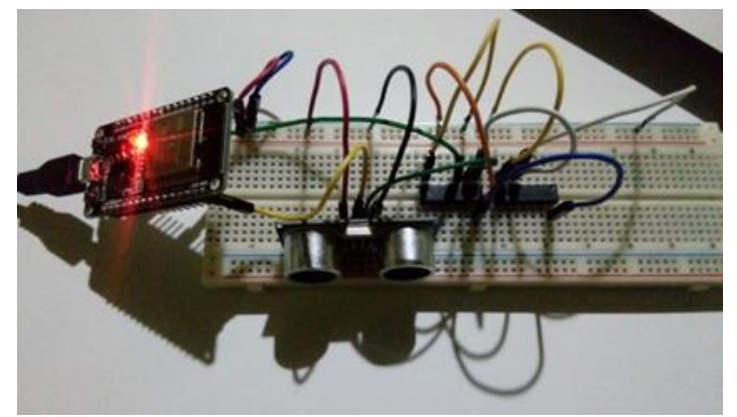

Figure 11. Connection of the first ultrasonic sensor with the ESP-32 module. 


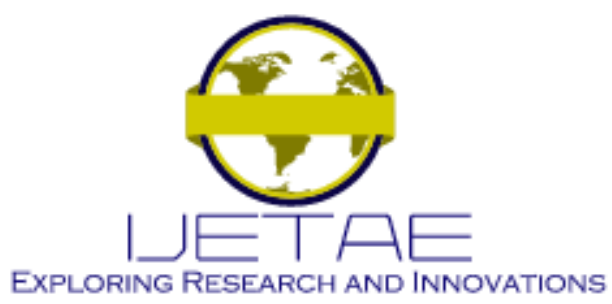

International Journal of Emerging Technology and Advanced Engineering

Website: www.ijetae.com (E-ISSN 2250-2459, Scopus Indexed, ISO 9001:2008 Certified Journal, Volume 12, Issue 01, January 2022)

\section{- Second ultrasonic sensor}

As shown in Figure 12, the same procedure was performed with the second ultrasonic sensor, but in this case, it will be responsible for measuring $80 \%$ of the waste container.

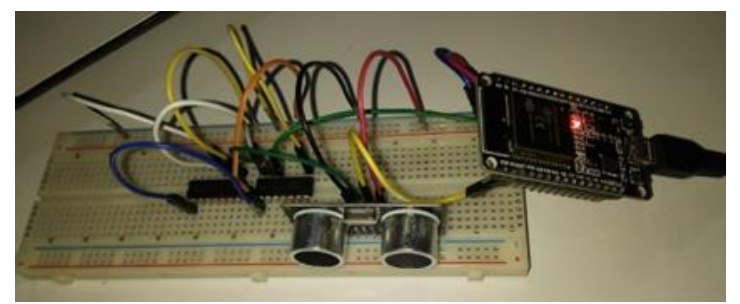

Figure 12. Connecting the second ultrasonic sensor with the ESP-32 module

When the first ultrasonic sensor detects obstacles, as well as sample in Figure 13, the system sends information through a web page regarding the status of the container, shown in Figure 14.

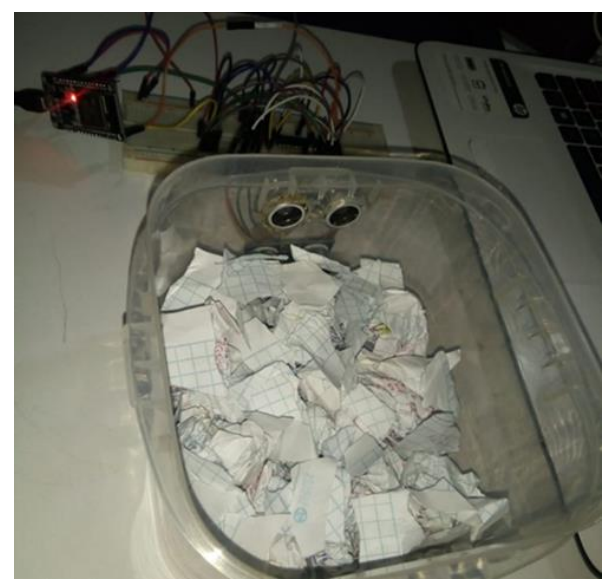

Figure 13. First sensor in obstacle arrest

\section{MONITORING THE GARBAGE CONTAINER}

\section{CONTAINER FILL LEVEL}

Recorded data

container $40 \%$
As shown the system will send information indicating " $40 \%$ container" if the first sensor detects obstacles.

When the first sensor and the second ultrasonic sensor detect obstacles, as well as sample in Figure 15, in the same way the system sent information through a web page regarding the state of the container, shown in Figure 16.

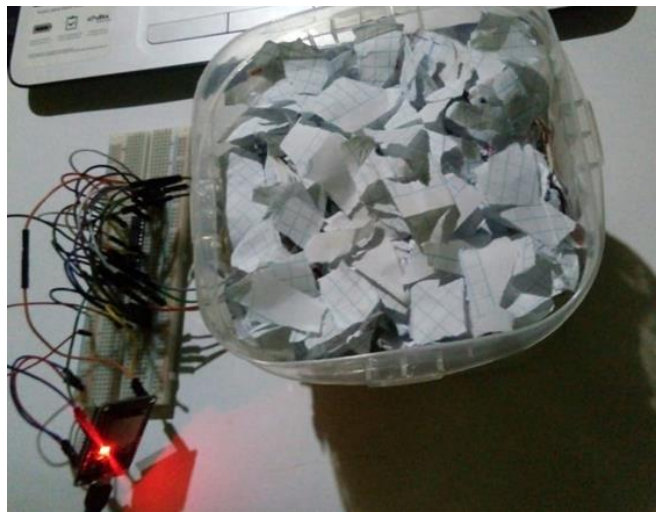

Figure 15. First sensor and second sensor in detection

\section{MONITORING THE GARBAGE CONTAINER}

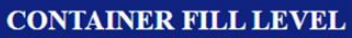

Recorded data

container $80 \%$ (available for collection)

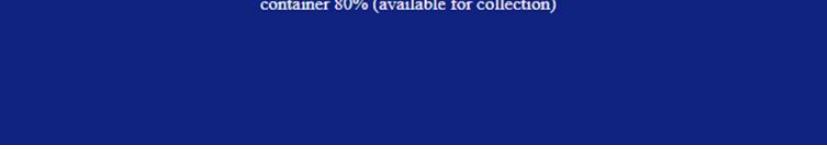

Figure $16.80 \%$ container status information

As shown the system will send information indicating " $80 \%$ container (available for collection)" if the first sensor and the second sensor detect obstacles.

Otherwise, when the ultrasonic sensors do not detect obstacles, as shown in Figure 17, the system will not send information regarding the state of the container, shown in Figure 18. 


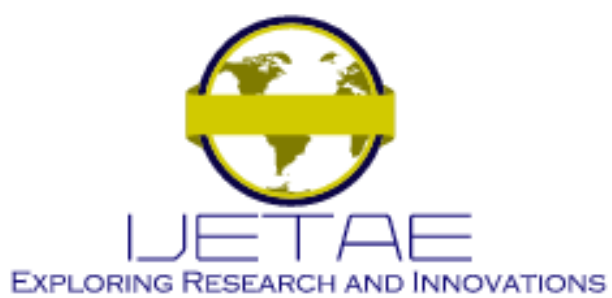

International Journal of Emerging Technology and Advanced Engineering

Website: www.ijetae.com (E-ISSN 2250-2459, Scopus Indexed, ISO 9001:2008 Certified Journal, Volume 12, Issue 01, January 2022)

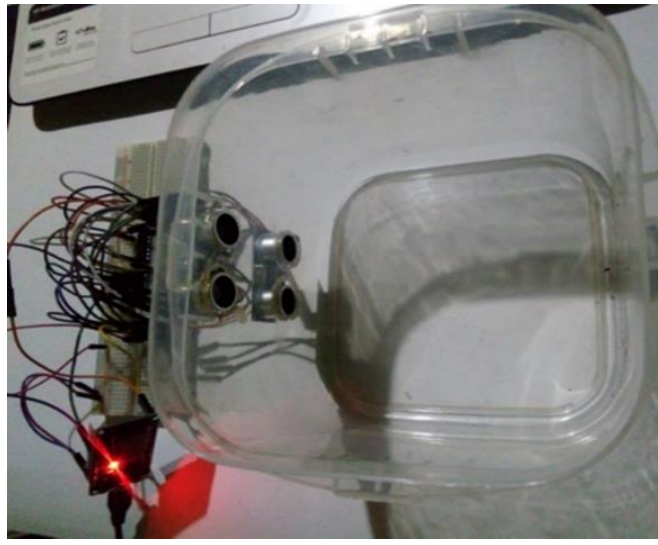

Figure 17. Unobstructed sensors

\section{MONITORING THE GARBAGE CONTAINER}

CONTAINER FILL LEVEL

Recorded data

As shown, the system will not send information because both sensors are not in a detection state.

The system shall be based on the following characteristics shown in Table IV.

TABLE IV.

Characteristics of the electronic devices used

\begin{tabular}{|c|c|}
\hline $\begin{array}{c}\text { Ultrasonic sensor distance } \\
\text { sensing range }\end{array}$ & $2 \mathrm{~cm}-220 \mathrm{~cm}$ \\
\hline $\begin{array}{c}\text { ESP } 32 \text { supply voltage } \\
\text { range }\end{array}$ & $2.55 \mathrm{v}-3.6 \mathrm{v}$ \\
\hline
\end{tabular}

If some type of moisture garbage remains near the ultrasonic sensors, there will be a small probability that the sensors will be damaged, but to reduce the risks the sensors are well protected with acrylic material, in addition, as indicated, the container of waste has drains in the part of the base that helps to minimize the humidity that exists inside.
To keep the sensors in good condition from time to time, they must be cleaned well, especially from the dust that accumulates in it and thus avoid problems in the performance of the system, which will also help the system to have a time of wider life.

In conclusion, the ultrasonic sensors are more exposed to damage than the esp32 module in case the correct maintenance is not carried out because they will oversee detecting the garbage that is inside the container, which mainly influences obstacles such as humidity and dust.

\section{DISCUSSIONS}

As is known in the research work, the esp32 module was used in order to provide information regarding what was recorded by the ultrasonic sensors, but otherwise in the author's research work [6] he used a Module emos d1 mini that like the esp32 allows to connect to the internet, but it has fewer functionalities, its implementation is due since I only use an ultrasonic sensor in each container.

In the research work the author [5] uses or more electronic devices to monitor garbage containers, such as the same ultrasonic sensor, a flame detector, Arduino uno, lora Shield and SmartBin sensor, regarding the research work a garbage container monitoring system was carried out, but with fewer electronic devices in order to allow monitoring of waste containers and reduce costs for their implementation.

how it could be observed in the work made a web page to be able to identify the state of the container by two percentages both $40 \%$ and $80 \%$ that indicates its collection, in the same way the authors [7] developed a web page that shows the containers in a certain area, which would be a map of containers in different locations where they are represented with colored icons that symbolize their respective states, they also used more electronic devices.

As observed in the research work, the monitoring system has two ultrasonic sensors located on the sides of the container to measure the amount of garbage in the, where the state of the container was represented by two different percentages and when the container was empty it did not detect anything, otherwise the authors are [14] made a monitoring system with a single ultrasonic sensor that is located on the lid of the garbage can so that it can measure the amount of garbage in it, where it allows to identify with colored LEDs the state of the bucket, which would be empty, half full and full. 


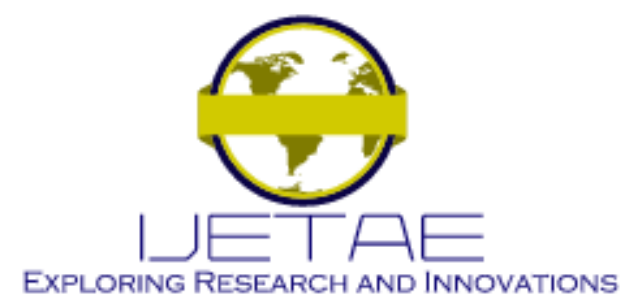

\section{International Journal of Emerging Technology and Advanced Engineering Website: www.ijetae.com (E-ISSN 2250-2459, Scopus Indexed, ISO 9001:2008 Certified Journal, Volume 12, Issue 01, January 2022)}

\section{CONCLUSIONS}

It is concluded that the system conducted is suitable for monitoring garbage containers from any point because the system allows you to connect to the internet through $\mathrm{Wi}-\mathrm{Fi}$ just by using the established ip address, it is also an economical and practical system, which is why it is an important alternative for cities that wish to improve the garbage collection process.

This system was made with the purpose of reducing environmental pollution and overall collection costs, as well as reducing the increase in garbage on the streets.

Finally, it is concluded that the system will improve the quality of life of the people who reside in the area where its implementation is desired, because it will reduce several types of problems that usually occur today, such as the proliferation of insects, rodents, bacteria, and microorganisms that cause diseases and unpleasant odors in the streets.

As a future project, it is undertaken to improve the system by implementing cameras near the garbage containers in order that these allow them to be classified in real time as full or not full, likewise it is also proposed to improve the website with the ability to create automatic routes for its respective collection, similar to what was proposed by the authors [15].

To implement the system there were certain limitations, one of them was to get the electronic devices because it took me a long time to acquirer. Another limitation was regarding the implementation of the system in the garbage container, due to the exponential increase in INFECTIONS by COVID 19, the implementation in a real garbage container could not be conducted, but a prototype was made where the electronic devices were placed to check their operation.

\section{REFERENCES}

[1] BBC News World, "'Global Garbage Crisis': 3 Shocking Figures on the Role of the United States - BBC News World," BBC News World,Jul. 08, 2019. https://www.bbc.com/mundo/noticias48914734 (accessed Dec. 06, 2021).

[2] E. Barboza Castillo and W. Achelus, "Participatory GIS for the environmental management of areas contaminated by solid waste in the UPZ galleries, Bogotá D.C. (Colombia)," Bogotá-Colombia, 2018. Accessed: Dec. 07, 2021. [Online]. Available: https://repository.udistrital.edu.co/bitstream/handle/11349/14666/Ba rbozaCastilloElgar2018. pdf? sequence=1\&isAllowed=y.

[3] E. G. Estrada Araoz, K. H. Huaypar Loayza, and H. J. Mamani Uchasara, "Environmental education and solid waste management in an educational institution in Madre de Dios, Peru," Cienc. Amaz. vol. 8, no. 2, pp. 239-252, Dec. 2020, doi: 10.22386/CA. V8I2.300.
[4] S. Purca and A. Henostroza, "Presence of microplastics in four sandy beaches of Peru," Rev. Peru. Biol. , vol. 24, no. 1, pp. 101-106, Apr. 2017, doi: 10.15381/RPB. V24I1.12724.

[5] M. F. Cavalier Jara, "Proposal for the design of an intelligent ecological container, to improve the management of urban solid waste in the district of Villa el Salvador," National Technological University of South Lima, Lima-Peru, 2019.

[6] S. K. Memon, F. Karim Shaikh, N. A. Mahoto, and A. Aziz Memon, "IoT based smart garbage monitoring \& collection system using WeMos \& Ultrasonic sensors," in 2019 2nd International Conference on Computing, Mathematics and Engineering Technologies (iCoMET),Mar. 2019, pp. 1-6, doi: 10.1109 / ICOMET.2019.8673526.

[7] N. Muyunda and M. Ibrahim, "Arduino-based smart garbage monitoring system: Analysis requirement and implementation," in 2017 International Conference on Computer and Drone Applications (IConDA),Jan. 2018, pp. 28-32, doi: 10.1109 / ICONDA.2017.8270394.

[8] A. Sivasangari, U. R. Polishetty, Ajitha, Anandhi, and R.M. Gomathi, "IoT based Smart Garbage System," in 2021 5th International Conference on Computing Methodologies and Communication (ICCMC),May 2021, pp. 506-509, doi: 10.1109 / ICCMC51019.2021.9418455.

[9] J.M. Garciaguirre Moreira, E. O. Coreas Flores, and T. Guadalupe Menjívar, "Implementation of IoT solution with ESP32 module and connectivity through WHITESpace TV infrastructure," SolTic UGB,vol. 3, no. 3, pp. 136-145, 2019, Accessed: Dec. 07, 2021. [Online]. http://ugb.edu.sv/revistas/index.php/soltic/article/view/70.

[10] E. Serrano-Pérez, "Approximation of Torricelli's law with Euler's method and an instrumented water tank with ultrasonic sensor," Iteckne,vol. 18, no. 1, pp. 52-56, Apr. 2021, doi: 10.15332/ITECKNE. V18I1.2540.

[11] G. Portillo, "Types of garbage containers: characteristics and waste | Green Renewables," RenovalesVerdes,2016. https://www.renovablesverdes.com/tipos-de-contenedores-de-basura/ (accessed Dec. 07, 2021).

[12] J. Ikiss, "Data acquisition system with ESP32," Universitat Politècnica de Catalunya, Barcelona-Spain, Oct. 2020. Accessed: Dec. $07, \quad 2021 . \quad$ [Online]. Available: https://upcommons.upc.edu/handle/2117/344400.

[13] C. Shetty, B. Dhananjaya, Deepa, and N. Rashmi, "Intelligent Sensors based Waste Disposal system for Smart Cities," in 2020 4th International Conference on Electronics, Communication and Aerospace Technology (ICECA),Dec. 2020, pp. 63-68, doi: 10.1109 / ICECA49313.2020.9297523.

[14] Y. Widiastiwi and C. A. Satria, "The Effectiveness of Utilizing IoTBased Smart Trash," in 2020 International Conference on Informatics, Multimedia, Cyber and Information System (ICIMCIS),Feb. 2021, pp. 290-295, doi: 10.1109 / ICIMCIS51567.2020.9354279.

[15] M. A. A. Ghazali, M. Kassim, N. Ya'acob, A. Idris, and S. Saaidin, "Mobile Application on Garbage Collector Tracker Using Google Maps," in 2019 IEEE 9th International Conference on System Engineering and Technology (ICSET),Nov. 2019, pp. 287-291, doi: 10.1109 / ICSEngT.2019.8906374. 